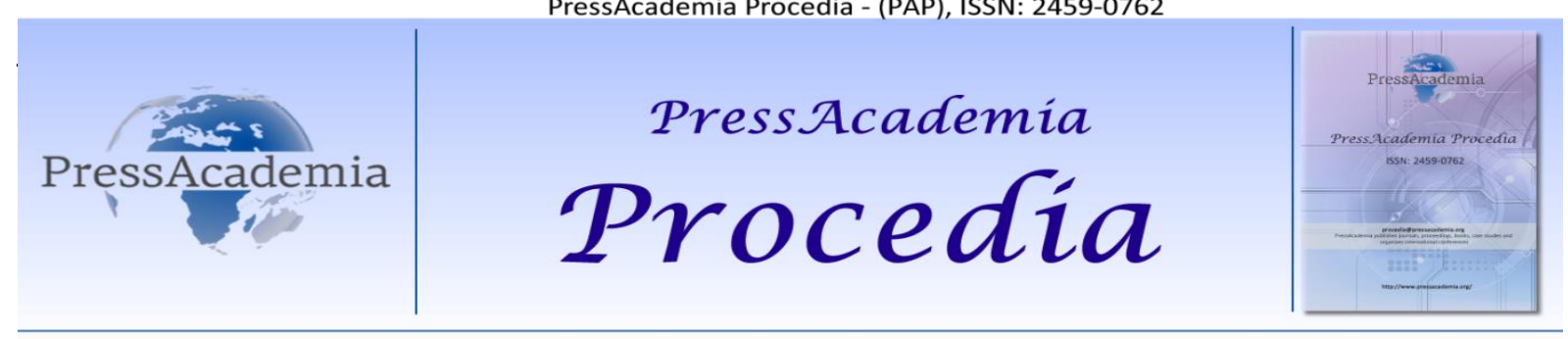

Global Business Research Congress (GBRC), May 24-25, 2017, Istanbul, Turkey.

\title{
EFFECTS OF TRANSFER OF UNDERTAKING ON COLLECTIVE LABOUR CONTRACTS
}

DOI: 10.17261/Pressacademia. 2017.420

PAP-GBRC-V.3-2017(35)-p. 358-362

\section{Ulas Baysal}

Istanbul Tecnical University, Istanbul, Turkey., baysalu@itu.edu.tr

\section{To cite this document}

Baysal, U., (2017), Effects of transfer of undertaking on collective labour contracts, PressAcademia Procedia (PAP), V.3, p.358-362

Permanent link to this document: $\underline{\text { http://doi.org/10.17261/Pressacademia.2017.420 }}$

Copyright: Published by PressAcademia and limited licenced re-use rights only.

\begin{abstract}
Article 6 of the Law No. 4857 envisions the principle of preservation of working conditions and the fate of labour contracts in the transfer of undertaking in line with the relevant regulations of the European Union. However, problematic issues in transfer of undertakings are not limited to individual labour contracts. One of the issues that arise on this topic is the question of how workers' working conditions will be affected by the transfer in terms of collective labour law. This may stem from the presence of a collective bargaining agreement in the transferred undertaking or from the presence of collective bargaining agreements in the undertakings at the same branch of industry owned by the transferee. Article 37 and 38 of the Law on Trade Unions and Collective Bargaining Agreements No. 6356 codifies the matter but remains unsatisfactory in resolving all of the issues that do or may arise.
\end{abstract}

Keywords: collective bargaining agreement, employee, employer, transfer of undertaking, working conditions JEL Codes: J52, K31

\section{IŞYERi DEVRININ TOPLU iş SÖZLEŞMELERINE ETKiLERi}

\section{ÖZET}

4857 sayılı Kanunun 6. maddesi, Avrupa Birliğinin konuya ilişkin düzenlemeleri ile paralel bir işyeri devirlerinde iş sözleşmelerinin akıbetini ve çalışma koşullarının korunması esasını öngörmektedir. Ancak işyeri devirlerinde ortaya çıkan sorunlar bireysel iş sözleşmeleri ile sınırlı değildir. Bu kapsamdaki sorunlardan biri, toplu iş hukuku bakımından devirden işçilerin çalışma koşullarının nasıl etkileneceğidir. Bu durum devredilen işyerinde bir toplu iş sözleşmesinin var olmasından kaynaklanabileceği gibi, devralan işverenin aynı işkolundaki işyerlerinde toplu iş sözleşmelerinin mevcut olmasından da kaynaklanabilir. 6356 sayılı Sendikalar ve Toplu i̇ş Sözleşmesi Kanununun 37 ve 38 . maddeleri konu hakkında düzenlemeler içermekle birlikte konu ile ilgili tüm sorunları çözmek bakımından yetersiz kalmaktadır.

Anahtar kelimeler: Toplu iş sözleşmesi, işçi, işveren, işyeri devri, çalışma koşulları

JEL Kodları: J52, K31 


\section{GíRiş}

Toplu iş sözleşmesi düzeni mevcut bir işyerinin devralınması halinde toplu iş sözleşmesinin akıbetine ilişkin olarak çıkacak problemlerin çözümü bakımından 6356 sayılı Sendikalar ve Toplu İ̧̧ Sözleşmesi Kanununda (STiSK) iki özel düzenlemeye yer verilmiştir. Bu düzenlemelerden ilki STiSK m. 37/1'dir. STiSK m.37/1 uyarınca "Toplu iş sözleşmesine taraf olan sendikanın tüzel kişiliğinin sona ermesi, faaliyetinin durdurulması, iş̧̧i sendikasının yetkiyi kaybetmesi ve toplu iş sözleşmesinin uygulandığı işyerlerinde işverenin veya işyerinin girdiği işkolunun değişmesi toplu işs sözleşmesini sona erdirmez". İşyerinin devri halinde de, işverenin değişmekte olduğundan toplu iş sözleşmesinin sona ermemesi kanunun getirdiği temel esastır. 2822 sayılı Toplu iş̧ Sözleşmesi, Grev ve Lokavt Kanunu döneminde de geçerli olan bu esas, uygulama bakımından ciddi sıkıntılar doğurmamaktadır.

Konuya ilişin ikinci düzenleme ise 6356 sayılı Kanunun 38. maddesinin 1. fıkrasıdır. 6356 sayılı Kanun m. 38/1'e göre "işletme toplu iş sözleşmesi kapsamında olan ya da toplu iş sözleşmesi bulunan bir işyeri veya işyerinin bir bölümünün devrinde, devralan işverenin aynı işkoluna giren işyeri veya işyerlerinde yürürlükte bir toplu işsözleşmesi var ise; devralınan işyeri veya işyerlerinde uygulanan toplu iş sözleşmesinden doğan hak ve borçlar, iş sözleşmesi hükmü olarak devam eder. Devralan işverenin işyeri ya da işyerlerinde uygulanan bir toplu iş sözleşmesi yok ise; devralınan işyerinde yürürlükteki toplu iş sözleşmesinden doğan hak ve borçlar, yeni bir toplu iş sözleşmesi yapılıncaya kadar toplu iş sözleşmesi hükmü olarak devam eder". Bildirimizin konusunu esas itibariyle STiSK m. 37/1 ve m.38/1 düzenlenen hususlarda ortaya çıkan sorunlar oluşturmaktadır. Toplu iş sözleşmesi bulunmayan bir işyerinin işletme toplu iş sözleşmesi tarafı olan bir işverence devralınması ve işyerinin bir bölümünün devrine bağlı olarak toplu iş ilişkileri bakımından ortaya çıkabilecek sorunlar bildirinin kapsamı dışında baırakılmıştır.

\section{TÜRK iş HUKUKUNDA işYYRI DEVRI VE TOPLU iş SÖZLEŞMESI KAVRAMLARI}

İşyerinin devri, sadece iş hukukunun konusu olmamakla birlikte, en önemli etkilerinden birini iş sözleşmeleri üzerinde yarattığından iş hukukuna ilişkin düzenlemelerde ayrıntılı olarak kendine yer bulmaktadır.

İş hukukuna ilişkin düzenlemelere değinmeden önce, işyeri devrinin Türk Borçlar Kanununda (TBK) genel bakımından düzenlendiğini ifade etmek gerekir. "Malvarlığının veya işletmenin devralınması" başlığını taşıyan TBK m.202'nin ilk fıkrası uyarınca "Bir malvarlığını veya bir işletmeyi aktif ve pasifleri ile birlikte devralan, bunu alacaklılara bildirdiği veya ticari işletmeler için Ticaret Sicili Gazetesinde, diğerleri için Türkiye genelinde dağıtımı yapılan gazetelerden birinde yayımlanacak ilanla duyurduğu tarihten başlayarak, onlara karşı malvarlığındaki veya işletmedeki borçlardan sorumlu olur".

Aynı düzenlemenin 2. fıkrası ise, 1. fıkrada belirtilen durumda eski borçlunun da, yeni borçlu ile birlikte iki yıl süreyle müteselsil olarak sorumlu kalacağını düzenlemektedir. Yine TBK m.202/2'ye göre "Bu süre, muaccel borçlar için, bildirme veya duyuru tarihinden; daha sonra muaccel olacak borçlar için ise, muacceliyet tarihinden işlemeye başlar". Hemen belirtelim ki TBK md.202/f.4 uyarınca bildirme veya ilanla duyurma yükümlülüğü devralan tarafından yerine getirilmedikçe, düzenlemenin ikinci fıkrasında öngörülen iki yıllık süre işlemeye başlamayacaktır. Ayrıca TBK m.202/3, borçların malvarlı̆̆ı veya işyeri devri ile üstlenilmesinin sonuçlarının, dış üstlenme sözleşmesinden doğan sonuçlarla özdeş olacağını düzenlemektedir.

İş mevzuatı ise, işyerinin devri halinde iş sözleşmelerinin akıbeti ve devreden işveren ile devralan işverenin sorumlulukları bakımından konuyu tanzim etmektedir. Bu itibarla 4857 sayılı İ̧̧ Kanununun 6. maddesinin "Iş̧yerinin veya bir bölümünün devri" şeklindeki başlığı "Iş̧yerinin veya bir bölümünün devrinin iş sözleşmelerine etkisi" olarak anlaşılmalıdır (Mollamahmutoğlu \& Astarlı \& Baysal, 2014: 269).

İş Kanunu m.6'da işyerinin veya bir bölümünün devrinin iş sözleşmelerine etkisi şu şekilde belirtilmektedir: "iş̧yeri veya işyerinin bir bölümü hukukî bir işleme dayalı olarak başka birine devredildiğinde, devir tarihinde işyerinde veya bir bölümünde mevcut olan iş sözleşmeleri bütün hak ve borçları ile birlikte devralana geçer.

Devralan işveren, iş̧̧inin hizmet süresinin esas alındığı haklarda, iş̧̧inin devreden işveren yanında işe başladığı tarihe göre işlem yapmakla yükümlüdür.

Yukarıdaki hükümlere göre devir halinde, devirden önce doğmuş olan ve devir tarihinde ödenmesi gereken borçlardan devreden ve devralan işveren birlikte sorumludurlar. Ancak bu yükümlülüklerden devreden işverenin sorumluluğu devir tarihinden itibaren iki yıl ile sınırlıdır".

TBK. m. 428'de de iş Kanunu ile paralel bir biçimde "IŞsyerinin tamamı veya bir bölümü hukuki bir işlemle başkasına devredildiğinde, devir tarihinde işyerinde veya bir bölümünde mevcut olan hizmet sözleşmeleri, bütün hak ve borçları ile birlikte devralana geçer" düzenlemesine yer verilmiştir. Yine iş Kanunu ile paralel şekilde, devreden işverenin müteselsil sorumluluğu, devir tarihinden itibaren iki yıl ile sınırlı tutulmuştur (Süzek, 2016: 217). 
Toplu iş sözleşmesi, toplu iş hukukunun temel kavramlarından biridir. STiSK $\mathrm{m} .2 / \mathrm{h}$ toplu iş sözleşmesini, iş sözleşmesinin yapılması, içeriği ve sona ermesine ilişkin hususları düzenlemek üzere işçi sendikası ile işveren sendikası veya sendika üyesi olmayan işveren arasında yapılan sözleşme olarak tanımlamaktadır. Toplu iş sözleşmesi, bir işyeri veya türüne göre birden fazla işyeri için yapııırken, işkolu esası dikkate alınmaktadır (Akyiğit, 2015: 558 vd.; Çelik \& Caniklioğlu \& Canbolat, 2016: 736 vd.; Narmanlıoğlu, 2016: 327 vd.; Sur, 2017: 268 vd.; Tuncay \& Savaş Kutsal, 2016: 208 vd.) İşyeri veya işletmede sözleşmeyi yapacak işçi sendikasının 6356 sayılı Kanunda öngörülen yetki şartlarını taşıması gerekmektedir. Kuşkusuz işyerinin devri, işyerinde veya işletmede hukuka uygun olarak bağıtlanmış mevcut toplu iş sözleşmesi bakımından da etkiler doğuracaktır. Bu etkilere ilişkin olarak aşağıda 6356 sayılı Kanunun m.37/1 ve m. 38/1 düzenlemeleri ele alınacaktır.

\section{STISK M.37/1 UYARINCA DEVREDILEN IŞYERINDEKi TOPLU iş SÖZLEŞMESININ AKIBETi}

Toplu iş sözleşmesi düzeni mevcut bir işyerinin devredilmesi halinde çeşitli ihtimaller mevcuttur. Bunlardan birincisi devralan işverenin aynı işkolunda bir işyerinin mevcut olmamasıdır. Bu ihtimalde devredilen işyerinde mevcut toplu iş sözleşmesine devrin önemli bir etkisi mevcut değildir. 2822 sayılı Toplu İ̧̧ Sözleşmesi, Grev ve Lokavt Kanununun "Tarafların durumunda değişiklik" başlığını taşıyan 8. maddesinde konu şu şekilde düzenlenmiştir: "Toplu iş sözleşmesine taraf olan sendikanın feshi veya infisahı yahut faaliyetten men edilmiş olması veyahut yetkiyi kaybetmiş olması veya toplu iş sözleşmesinin uygulandığı işyerlerinde işverenin değişmesi toplu iş sözleşmesini sona erdirmez". 6356 sayılı Kanunun 37. Maddesi de konuyu çok benzer biçimde düzenlemektedir. STiSK m. 37/1 uyarınca "Toplu iş sözleşmesine taraf olan sendikanın tüzel kişiliğinin sona ermesi, faaliyetinin durdurulması, iş̧̧i sendikasının yetkiyi kaybetmesi ve toplu iş sözleşmesinin uygulandığı işyerlerinde işverenin veya işyerinin girdiği işkolunun değişmesi toplu iş sözleşmesini sona erdirmez". Dolayısıyla işyerinde mevcut olan toplu iş sözleşmesi sona ermeyecek, olduğu haliyle varlığını devam ettirecektir (Akyiğit, 2015: 551; Tuncay \& Savaş Kutsal, 2016: 298-299; Tunçomağ \& Centel, 2015: 406). Varlığını devam ettirecek hükümler toplu iş sözleşmesinin normatif kısmı ile sınırlı değildir, borç doğurucu hükümler de varlığını sürdürecek, dolayısıyla işyerini devralan işvereni bağlayacaktır (Çelik \& Caniklioğlu \& Canbolat, 2016: 827-828).

Burada tartışıması gereken bir başka nokta, devre konu işyerinin bir grup toplu iş sözleşmesi kapsamında olması halidir. 6356 sayılı Kanun m.2/ç'de işçi sendikası ile işveren sendikası arasında, birden çok üye işverene ait aynı işkolunda kurulu işyerlerini ve işletmeleri kapsayan toplu iş sözleşmesi olarak tanımlanan grup toplu iş sözleşmesine dahil bir işyerini devralan işveren, devir ile birlikte toplu iş sözleşmesi ile bağı hale gelecektir (Ekonomi, 2000: 359; Güzel \& Ugan Çatalkaya, 2014 : 181).

Daha sorunlu husus ise işletme toplu iş sözleşmelerine ilişkindir. 6356 sayılı Kanunun 2. maddesinde (d bendi) işletme toplu iş sözleşmesi, bir gerçek veya tüzel kişiye ya da bir kamu kurum veya kuruluşuna ait aynı işkolundaki birden çok işyerini kapsayan sözleşme olarak tanımlanmıştır. İşletme toplu iş sözleşmesi kapsamında olan bir işyerinin devri halinde mevcut toplu iş sözleşmesinin devralan işveren açısından bir anlam ifade etmeyeceği de savunulmakla birlikte, STiSK m.37/1 lafzı ve ruhu dikkate alındığında böyle bir yorumu dışlamaktadır. Burada işyerinde uygulanan işletme toplu iş sözleşmesinin sınırlı da olsa devralan işvereni bağlayacağı kabul edilmelidir (2822 sayılı Kanun döneminde bu soruna ilişkin olarak bkz. Şahlanan, 2000: 20).

\section{STiSK M.38/1'DE DÜZENLENEN HALLERDE DEVREDILEN işYERINDEKi TOPLU iş SÖZLEŞMESININ AKIBETi}

6356 sayılı STiSK m. 38/1 iki hali düzenlemektedir. Bunlardan birincisi işyerini devralan işverenin, aynı işkolunda başka bir işyeri veya işyerlerinin bulunması ve burada/buralarda yürürlükte bir toplu iş sözleşmesinin bulunmasıdır (c.1). Fıkrada yer alan ikinci düzenleme ise devralınan işverenin işyeri ya da işyerlerinde uygulanan bir toplu iş sözleşmesi olmaması ihtimaline ilişkindir(c.2). Aşağıda her iki duruma ilişkin olarak önce ikinci cümlede düzenlenen ihtimal, sonrasında ise birinci cümledeki ihtimal ve bu çerçevede STiSK m. 36/1'de düzenlenen yararlılık ilkesinin uygulanmasına ilişkin ortaya çıkan sorunlar ele alınacaktır.

\subsection{STiSK m. 38/1, c.2'de Düzenlenen Ihtimal}

STiSK m.38/l, c.2 genel olarak işyerinin, herhangi bir toplu iş sözleşmesine taraf olmayan işveren tarafından devralınması halinde işyerinde mevcut toplu iş sözleşmesinin akıbetini düzenlemektedir. STiSK m.38/l, c.2'ye göre, "Devralan işverenin işyeri ya da işyerlerinde uygulanan bir toplu iş sözleşmesi yok ise; devralınan işyerinde yürürlükteki toplu iş sözleşmesinden doğan hak ve borçlar, yeni bir toplu iş sözleşmesi yapılıncaya kadar toplu iş sözleşmesi hükmü olarak devam eder". Doktrinde düzenleme, devredilen işyerinde uygulama bulan toplu iş sözleşmesi türü bakımından herhangi bir ayrım yapılmaması, her tür toplu iş sözleşmesi düzenlemesinin kapsama alınması bakımından isabetli bulunurken, STiSK m.36/II ile uyumsuz olduğu, STiSK m.35/I-III ile çeliştiği ve vazedilmesindeki amacın aşıldığı gerekçesiyle eleştirilmiştir (Akyiğit, 2015: 552; Alpagut, 2012: 35; Güzel \& Ugan Çatalkaya, 2014: 181 Yayvak, 2014: 71). Bu noktada eleştirilere katılamamak zordur, çünkü süresi bakımından açık uçlu bir toplu iş sözleşmesi 6356 sayılı Kanunun farklı düzenlemeleri ile olduğu kadar Kanunun temel yapısı ile de çelişmektedir. Olması gereken hukuk bakımından, makul bir çözüm, devredilen işyerindeki toplu iş 
sözleşmesinin süresinin sona ereceği ana kadar bir toplu iş sözleşmesi olarak, süresinin sona ermesinden sonra ise içerdiği düzenlemelerin iş sözleşmesi hükmü olarak varlığını korumasıdır (Yayvak, 2014: 72).

\subsection{STiSK m. 38/1, c.1'de Düzenlenen intimal}

6356 sayılı Kanun m. 38/1'in birinci cümlesine göre "İ̧̧letme toplu iş sözleşmesi kapsamında olan ya da toplu iş sözleşmesi bulunan bir işyeri veya işyerinin bir bölümünün devrinde, devralan işverenin aynı işkoluna giren işyeri veya işyerlerinde yürürlükte bir toplu iş sözleşmesi var ise; devralınan işyeri veya işyerlerinde uygulanan toplu işsözleşmesinden doğan hak ve borçlar, iş sözleşmesi hükmü olarak devam eder".

STiSK m. 38/1'de düzenlenen ilk ihtimalde devredilen işyeri bir işletme toplu iş sözleşmesi kapsamında yer almaktadır. Bir başka deyişle devreden işverenin aynı işkolunda birden fazla işyeri mevcuttur ve aynı işkolunda yer alan bu işyerleri bakımından işletme toplu iş sözleşmesi yapmak bakımından yetkiye sahip tüm bu işyerleri için bir toplu iş sözleşmesi bağıtlanmıştır. İşverenin aynı işkolunda yeni bir işyeri devralmasının sonucu kanun hükmünde göre devralınan işyerindeki toplu iş sözleşmesinden doğan hak ve borçların iş sözleşmesi hükmü olarak devam etmesidir. Burada devredilen işyerindeki toplu iş sözleşmesindeki normatif hükümler etkisi azalarak varlıklarını sürdürürken, borç doğurucu hükümler ortadan kalkmakta, toplu iş sözleşmesi bir nev'i sona ermektedir (Sur, 2017: 319; Yayvak, 2014: 69).

STiSK m.38/1, c.1 ile amaçlanan devir sonrasında, işverenin aynı işkolundaki birden fazla işyerinin mevcut olması ile oluşan toplu iş sözleşmesi biriminde, sadece bir işletme toplu iş sözleşmesinin mevcudiyetinin sağlanmasıdır (Güzel \& Ugan Çatalkaya, 2014: 189). Düzenleme ile 2822 sayılı Toplu iş Sözleşmesi, Grev ve Lokavt Kanunu döneminde yaşanan belirsizlik ortadan kaldırılmıştır. Ancak düzenleme, doktrinde devre konu işyerindeki toplu sözleşme hükümlerinin, normatif olma özelliğini yitirerek, iş sözleşmesi hükmü haline gelecekleri ve 4857 sayılı İ̧̧ Kanunu m.22 uyarınca, iş̧̧ilerin yazılı onayı alınmak suretiyle, toplu iş sözleşmesinde yer alan çalışma koşulları veya haklar bakımından esaslı değişiklik yapılmasının olanaklı hale geleceği, toplu iş sözleşmesiyle sağlanan hakların korunmasında geri düşüleceği ve düzenlemenin Avrupa Birliği'nin 2001/23 sayılı Yönergesinde öngörülen, mevcut toplu iş sözleşmesi hükümlerinin en az bir yıl iş̧̧i aleyhine değiştirilemeyeceği kuralı ile çeliştiği gerekçeleriyle eleştirilmektedir(Alpagut, 2012: 34; Güzel \& Ugan Çatalkaya, 2014: 189; Sur, 2017: 319). Bu noktada Avrupa Birliği'nin 2001/23 sayılı Yönergesi m.3/3'deki “Devri takiben devralan varolan toplu sözleşmenin sona ermesine veya bir başka toplu sözleşmenin geçerli olmasına kadar devralana uygulanabilme kabiliyeti olan varolan toplu sözleşme hükümlerine uyar. Üye Devletler söz konusu toplu sözleşme hükümlerinin uygulanmasına 1 yıldan azolmamak üzere sınır getirebilir" hükmü de dikkate alınarak, Türk kanun koyucusunun toplu iş sözleşmesinin normatif hükümlerini, toplu iş sözleşmesi niteliğinden çıkararıp iş sözleşmesi niteliği tanıması ile devredilen işyerindeki iş̧̧iler devralan işverene ait aynı işkolunda bulunan işyerlerindeki toplu iş sözleşmesinden yararlanma imkân sağladığı söylenebilecektir (Benzer doğrultuda bkz. Canbolat, 2013:170,171; aksi yönde bkz. Akyiğit, 2015: 554; Alpagut, 2013:179).

\section{SONUÇ}

İşyeri devri sonrasında, iş sözleşmelerinin akıbetine ilişkin problemlerin 2003 tarihli 4857 sayılı iş Kanunu ile büyük ölçüde çözülmüş olmasının ardından, işyerinde uygulanmakta olan toplu iş sözleşmesinin akıbetine ilişkin sorunların da ciddi bir bölümü 2012 tarihli ve 6356 sayılı Sendikalar ve Toplu İ̧̧ Sözleşmesi kanunu ile çözüme kavuşturulmuştur. STiSK m.37/1 ve m.38/1 düzenlemeleri konu hakkındaki genel esasları ortaya koymaktadır. Ancak söz konusu düzenlemelerde, yukarıda açıklandığı üzere eksik bırakılan noktalar da mevcuttur. Özellikle STiSK m. 38/1,c.2'de işyeri devri halinde açık uçlu bir toplu iş sözleşmesi düzeni yaratılması ve STiSK m. 38/1,c.1'de devredilen işyerindeki işçilerin devaralan işverene ait aynı işkolunda bulunan işyerlerindeki toplu iş sözleşmesinden yararlanıp yararlanamayacakları hususu, söz konusu düzenlemelerin uygulamada sorunlar yaratabilecek nitelikte eksiklikleridir.

\section{KAYNAKLAR}

Akyiğit, E. (2015), Toplu İş Hukuku, Seçkin Yayıncılık, Ankara.

Alpagut, G., (2012), Alpagut, G.: 6356 Sayılı Yasanın Toplu İş Sözleşmesi ve Toplu İş Uyuşmazlıklarına iliş̧kin Hükümlerinin Değerlendirilmesi Uluslararası Normlara Uyum, Legal İş Hukuku ve Sosyal Güvenlik Hukuku Dergisi, 2012, C.9, S. 35, s.25-55.

Alpagut, G., (2013), İş Hukukunda Güncel Sorunlar (3), Seminer 22 Aralık 2012, Kadir Has Üniversitesi Hukuk Fakültesi, Seçkin Yayıncılık, Ankara.

Canbolat, T. (2013), İş Hukukunda Güncel Sorunlar (3), Seminer 22 Aralık 2012, Kadir Has Üniversitesi Hukuk Fakültesi, Seçkin Yayıncılık, Ankara.

Çelik N., Caniklioğlu, N., Canbolat, T. (2016), İş Hukuku Dersleri, Beta Basım, İstanbul.

Ekonomi, M. (2000), “İşyerinin Bir Bölümünün Devri (Kısmi Devir) ve İş İlişkilerine Etkisi”, Prof. Dr. Turhan Esener’e Armağan, Ankara. 
Güzel, A., Ugan Çatalkaya D. (2014), "işyerinin veya Bir Bölümünün Devrinin Toplu İ̧̧ Sözleşmesine Etkisi”, Dokuz Eylül Üniversitesi Hukuk Fakültesi Dergisi Cilt: 15, Özel S., s.147-199.

Mollamahmutoğlu H., Astarlı M., Baysal U. (2014), iş̧ Hukuku, Turhan Kitabevi, Ankara.

Narmanlıŏlu, Ü. (2016), Toplu Iş iliş̧kileri, Beta Basım, İstanbul.

Sur, M. (2017), iş Hukuku Toplu ilişkiler, Turhan Kitabevi, Ankara.

Süzek, S. (2016), iş Hukuku, Beta Basım, İstanbul.

Şahlanan, F. (2000), "işsverenin Değişmesi-Iş̧yerinin Devri ve iş̧ Hukukuna ilişkin Sonuçları", TÜHis İş Hukuku ve ikktisat Dergisi, C.16, S.4-5. s.14-24.

Tuncay, C., Savaş Kutsal F.B. (2016), Toplu iş Hukuku, Beta Basım, İstanbul.

Tunçomağ K., Centel T. (2015), İ̧̧ Hukukunun Esasaları, Beta Basım, İstanbul.

Yayvak, i. (2014), Toplu İs Sözleşmesinin Art Etkisi, Beta Basım, ìstanbul. 